\title{
Balanço de radiação de copas de cafeeiros em renques e suas relações com radiação solar global e saldo de radiação de gramado
}

\author{
Felipe Gustavo Pilau (*); Luiz Roberto Angelocci \\ Escola Superior de Agricultura “Luiz de Queiroz” (ESALQ/USP), Departamento de Engenharia de Biossistemas, Av. Pádua Dias, 11. \\ 13418-900 Piracicaba (SP), Brasil. \\ (*) Autor correspondente: fgpilau@usp.br
}

Recebido: 28/maio/2014; Aceito: 8/jul./2014

\begin{abstract}
Resumo
Devido à importância da quantificação da radiação solar interceptada e absorvida por plantas foram realizadas medidas do saldo de radiação (Rnc) de copas em um trecho de renque de cafeeiros, analisando-se o efeito de diferentes áreas foliares no renque e correlacionando-os com dados de radiação solar global $(\mathrm{Qg})$ e saldo de radiação de gramado (Rn). Para a mensuração nos cafeeiros foi utilizado um sistema de integração espaço-temporal com saldo-radiômetros móveis. Os resultados evidenciam uma relação direta porém não proporcional entre Rnc e área foliar das plantas. As relações de Rnc com Qg são específicas para cada área foliar. Os dados não sustentam a hipótese de que o saldo de radiação normalizado por unidade de área foliar seja uma função linear do saldo de radiação de gramado.
\end{abstract}

Palavras-chave: saldo de radiação, área foliar, variáveis meteorológicas, Coffea arabica L.

\section{Radiation balance of coffee tree tops in hedgerows and its relations with global solar and grass net radiations}

\begin{abstract}
Intercepted solar radiation (ISR) is important for plant growth, development and energy fluxes. We used a mobile device carrying on eight net radiometers encompassing coffee plants aligned in hedgerows to measure Rnc. Measures of radiation balance over several coffee hedgerows (Rnc) were taken in order to analyze the effect of leaf area (LA) on ISR as well as its relationship with solar radiation $(\mathrm{Qg})$ and grass net radiation $(\mathrm{Rn})$. Results showed a direct relationship between LA, Rnc and Qg. However, these relations were not linear, which leads us to refute the hypothesis that the normalized Rnc in terms of leaf area would be a linear function of the grass net radiation.
\end{abstract}

Key words: net radiation, leaf area, meteorological variables, Coffea arabica L.

\section{INTRODUÇÃO}

A radiação solar interceptada e absorvida por plantas é fonte exclusiva de energia para seus processos físicos, fisiológicos e bioquímicos, sendo de grande importância para determinação do acúmulo de massa seca e produção (Jaramillo-Botero et al., 2010), da perda de água pela vegetação (Flumignan e Faria, 2009; Marin et al., 2003) e de características de seu microclima (Karasawa et al., 2007; Righi et al., 2007).

A grande maioria dos estudos teóricos e experimentais de balanço de radiação em comunidades vegetais concentra-se principalmente em dosséis com distribuição homogênea das plantas no plano horizontal (André et al., 2010; Sauer et al., 2007; Souza et al., 2010). Nas últimas décadas, com vistas à melhor compreensão do consumo de água e da fotossíntese na escala da planta, tem-se investido no estudo da interaçáo da energia radiante em copas de espécies arbóreas que formam dosséis descontínuos (Angelocci et al., 2004; 2008; Green et al., 2001; Landsberg et al., 1975; McNaughton et al., 1992; Thorpe, 1978).

A mediçáo direta do balanço de radiaçáo da copa de arbóreas é relativamente complexa, como referendam as metodologias descritas por Landsberg et al. (1975) e McNaughton et al. (1992) e suas adaptações (Angelocci et al., 2004), exigindo estrutura específica e grande número de sensores nas determinações, além da superação de dificuldades originárias da geometria e da dimensão das copas.

Assim, buscam-se formas de estimativa da radiação interceptada pela copa e da sua absorção pelo uso de modelagem físico-matemática (Carrasco e Ortega-Farías, 
2008; Green et al., 2003; Oyarzún et al., 2007), algumas vezes assumindo uma extinção exponencial da radiação solar no interior do dossel vegetal (Jackson e Palmer, 1979; Ritchie, 1972). Formas ainda mais simplificadas buscam correlacionar o saldo de radiação da copa às variáveis rotineiramente medidas nas estaçôes agrometeorológicas, como radiação solar global e saldo de radiação de gramado (Angelocci et al., 2008; Pereira et al., 2007), ainda que esse tipo de procedimento seja mais restritivo do que o uso de modelagem quanto à possibilidade de transferência de resultados para outras condiçôes de crescimento da cobertura vegetal.

Neste trabalho, as medidas de saldo de radiaçáo de copas em um trecho de renque, determinadas pelo sistema de integração espaço-temporal com saldo-radiômetros móveis, foram correlacionadas com dados de radiação solar global e saldo de radiação de gramado, em períodos de $15 \mathrm{~min}$, horários e diurnos, com o objetivo de analisar como tais relaçôes são afetadas pelas escalas temporais de medida e, também, pelas diferentes áreas foliares no renque.

\section{MATERIAL E MÉTODOS}

O trabalho foi conduzido no município de Piracicaba,

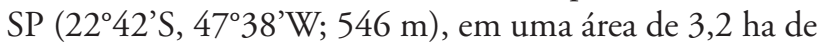
cafezal (Coffea arábica L.) com 3 anos de idade. O solo da área foi classificado como Nitossolo Vermelho.

Os cafeeiros cv. Obatã IAC 1669-20 eram espaçados em 3,5 $\mathrm{m} \times 0,9 \mathrm{~m}$, com silhueta da folhagem com formato aproximadamente paralelepipedal no maior sentido do renque, com 1,1 m de altura e 1,0 m de largura, começando a ramagem a ocorrer a partir de $10-20 \mathrm{~cm}$ do solo. A orientação das linhas de plantio era sudeste-noroeste, com azimute $161^{\circ}$. O trecho de renque $(4,7 \mathrm{~m})$ selecionado para o estudo era centralizado no cafezal, com amostragem de cinco plantas na linha, que representavam bem a população do cafezal quanto a tamanho e área foliar por planta. A área de entrelinhas era coberta por vegetação espontânea, mantida constantemente roçada a $\pm 15 \mathrm{~cm}$ de altura.

Para determinar a área foliar (AF) dos cafeeiros amostrados, uma contagem manual do número total de folhas (NTF) foi realizada em cada cafeeiro. Com régua milimetrada foram medidos o comprimento (C) e a largura (L) de 100 folhas em cada planta. Assim, considerando o tamanho médio das folhas, a AF foi determinada a partir da equação 1 (Benincasa, 2003):

$A F=C . L . N T F . C$

em que c é um fator empírico obtido experimentalmente no cafezal e igual a 0,6862 , muito próximo aos obtidos para outras variedades de cafeeiro por Angelocci et al. (2008), Gomide et al. (1977) e Marin et al. (2005).
Em 2004, no mês de agosto, as plantas já com baixa área foliar no início do mês devido à desfolha natural pela deficiência hídrica no período, acabaram sofrendo queda adicional de folhas devido à derriça dos frutos, permitindo uma primeira avaliação do efeito da densidade de folhagem sobre o balanço de radiaçáo do cafeeiro. No ano seguinte, 2005, a partir do conhecimento da área foliar inicial dos cafeeiros, foram executadas desfolhas manuais forçadas, a fim de complementar a análise do efeito da folhagem sobre o balanço de radiação. Nessa ocasiáo, cada desfolha almejava remover cerca de 2,0 $\mathrm{m}^{2}$ de AF por planta. Do número total de folhas retiradas de cada planta, 20\% tinham suas dimensões $\mathrm{L}$ e $\mathrm{C}$ mensurados. Com esses dados, a partir da equação 1 foi possível confirmar o valor real da área foliar removida e, por subtração, da $\mathrm{AF}$ restante.

As medições do saldo de radiação, a partir de um sistema móvel de integração espaço-temporal, foram realizadas em 74 dias, não consecutivos. Ao todo foram 13 dias entre os meses de agosto e setembro de 2004 e outros 61 dias entre fevereiro e maio de 2005.

O saldo de radiaçáo foi mensurado por oito saldoradiômetros modelo Q7.1 (Radiation and Energy Balance Systems, Seattle, WA, USA), cujas placas sensoras tangenciavam as paredes hipotéticas de um cilindro nocional que englobava o comprimento de 4,7 $\mathrm{m}$ de linha de plantio. Os oito sensores foram fixados a cada intervalo de $45^{\circ}$, ficando então suas placas sensoras posicionadas perpendicularmente aos raios de um círculo com $1,46 \mathrm{~m}$ de diâmetro em torno do renque (Figura 1). Uma armação circular de ferro sustentava os radiômetros, sendo ela impulsionada, com os sensores, no sentido do renque, movendo-se sobre dois trilhos paralelos dispostos nesse sentido e apoiados sobre o solo. As mediçóes eram feitas continuamente, através de movimentos alternados de ida e volta da armação de ferro, sendo essa tracionada por corrente metálica acoplada a uma caixa redutora de rotação e um motor elétrico de $0,75 \mathrm{HP}$. Ao alcançar cada extremidade dos trilhos o sistema tinha seu movimento automaticamente invertido pelo uso de um sistema mecânico. Tempo para um percurso de ida e volta ao longo dos 4,7 $\mathrm{m}$ de renque: 40 segundos. O número de saldo-radiômetros utilizados seguiu as orientaçôes de Landsberg et al. (1975) e Thorpe (1978).

Dessa forma, medidas de todos os saldo-radiômetros móveis foram registradas à frequência de $1 \mathrm{~Hz}$ pelo uso de datalogger modelo CR21 (Campbell Inc., Logan, UT, USA) acoplado ao arco em movimento, podendo ser integradas nas escalas de tempo desejadas. As mediçóes formaram, assim, um sistema balanceado de radiações de entrada e de saída do renque, assumindo-se que os oito pontos de medida eram representativos dos fluxos globais (de entrada e de saída) de radiação nas copas. Na geometria cilíndrica assim adotada, cada radiômetro amostra $1 / 8 \mathrm{da}$ área lateral do cilindro nocional, desconsiderando-se as trocas energéticas das duas bases do cilindro, chegando-se assim à equação 2 , que integra 
a)

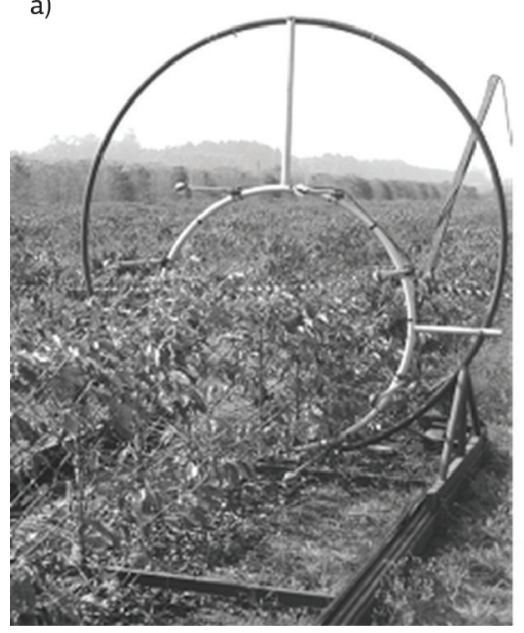

b)

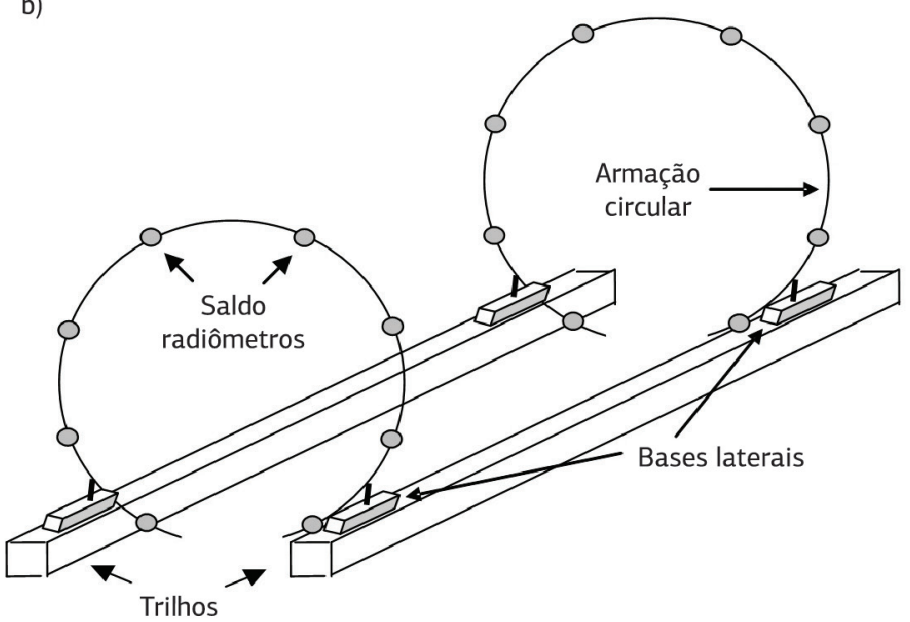

Figura 1. Visão geral do sistema móvel, destacando-se a armação circular metálica utilizada para cafeeiros jovens (menor), com os saldoradiômetros acoplados (a) e uma perspectiva da estrutura e do movimento linear, formando uma geometria cilíndrica nocional de medida (b).

o saldo de radiação (Rnc) de um segmento de renque no intervalo de tempo de medida adotado. A geometria de distribuição dos sensores contornando circularmente a copa e a integração das medidas foram originalmente proposta por Thorpe (1978), mas com uso de saldo-radiômetros fixos e não em varredura ao longo da linha de plantio, como adotado neste trabalho, o que melhora a amostragem.

$R n c=\frac{\left(\frac{1}{8} \sum_{i=1}^{8} R n i\right) \cdot d_{h} \cdot 2 \cdot \pi \cdot r}{N p}$

em que Rni é a medida do balanço de radiação de cada saldo radiômetro; $\mathrm{d}_{\mathrm{h}}$ é a distância horizontal do trecho medido; $\mathrm{r}$ é o raio do cilindro imaginário de medição; e Np é o número de plantas na distância $\mathrm{d}_{\mathrm{h}}$.

Dados de radiação solar global $(\mathrm{Qg})$ (piranômetro marca Kipp \& Zonen, modelo CM-3, faixa espectral: 0,3 a $2,8 \mu \mathrm{m}$, sensibilidade: 5 a $20 \mu \mathrm{V} / \mathrm{W} / \mathrm{m}^{2}$ ) e saldo de radiação de gramado $(\mathrm{Rn})$ (saldo-radiômetro marca Rebs, modelo Q7.1, faixa espectral: 0,25 à $60 \mu \mathrm{m}$, sensibilidade: 9,6 $\mathrm{W} \mathrm{m}^{-2} \mathrm{mV}^{-1}$ para valores positivos; 11,9 $\mathrm{W} \mathrm{m}^{-2} \mathrm{mV}^{-1}$ para valores negativos) foram medidos e registrados em W m${ }^{-2}$, na frequência de $1 \mathrm{~Hz}$, e armazenados como média de 15 minutos na estação meteorológica da ESALQ/USP, distante $150 \mathrm{~m}$ dos cafeeiros utilizados. Os saldo-radiômetros, tanto instalados em movimento em torno dos cafeeiros como aquele instalado na estação meteorológica, foram aferidos tendo por referência um saldo-radiômetro de mesma marca recém- adquirido, usando-se a calibragem do fabricante, enquanto que o radiômetro global foi aferido periodicamente em relação a um radiômetro espectral marca Eppley.

\section{RESULTADOS E DISCUSSÃO}

Para quantificar o efeito da área foliar sobre a absorção de energia radiante pelo trecho de renque de cafeeiros minimizando a influência da declinação solar e da disponibilidade de energia radiante, optou-se por breves períodos de medição para cada situação de área foliar. Realizaram-se um mínimo de cinco e um máximo de 27 dias de mediçóes em cada série de medidas, num período de dois e três meses consecutivos, respectivamente nos anos 2004 e 2005 (Tabela 1).

Em 2004, a redução da área foliar dos cafeeiros pela colheita manual possibilitou medir o balanço de radiação com AF média de 3,64 $\mathrm{m}^{2} \mathrm{pl}^{-1}$ e, em sequência, com uma área foliar 60\% menor (Tabela 1). Em 2005, seis meses após as amostragens com AF de $1,42 \mathrm{~m}^{2} \mathrm{pl}^{-1}$, devido à estação de crescimento no período chuvoso e ao efeito positivo dos tratos culturais, o renque foi primeiramente avaliado com uma AF média por planta bem superior, de $11,36 \mathrm{~m}^{2} \mathrm{pl}^{-1}$ (Tabela 1).

As características de variação temporal da disponibilidade de irradiância solar global e ângulo de incidência da radiação solar direta em relação ao plano vertical do renque acabam por influenciar o balanço de radiação da copa. Além disso, folhas com idades diferentes e em distintas épocas do ano normalmente apresentam diferentes coeficientes de reflexão, com interferência direta no balanço de radiaçáo da vegetação (Sentelhas e Nascimento, 2003; Souza Filho et al., 2006), mas essas particularidades (idade das folhas e estaçôes do ano) náo foram estudadas de forma específica e direta neste trabalho, embora na época de frutificação tenha-se detectado um possível efeito no coeficiente de reflexão de ondas curtas, como será discutido adiante. Para ilustrar a magnitude de variação da irradiância solar diária e o valor 
relativo do saldo de radiação da copa por unidade de área foliar (Rnc/AF), seus valores são mostrados na figura $2 \mathrm{em}$ função do número sequencial do dia em cada ano (NDA).

Desconsiderando a disponibilidade de energia radiante (Qg), dentre todas as AF avaliadas, os valores máximo e mínimo do saldo de radiação das copas por unidade de área foliar dos cafeeiros (Rnc/AF) foram de $1,84 \mathrm{MJ} \mathrm{m}^{-2} \mathrm{dia}^{-1} \mathrm{e}$ $0,39 \mathrm{MJ} \mathrm{m}^{-2} \mathrm{dia}^{-1}$ (Figura 2), assemelhando-se aos registrados por Angelocci et al. (2008) para Coffea arabica L. cv. Mundo Novo com 5 anos de idade. Pereira et al. (2007) apresentam conjunto de dados de saldo de radiaçáo por unidade de área foliar de cinco diferentes espécies arbóreas que partem de aproximadamente $0,5 \mathrm{MJ} \mathrm{m}^{-2}$ dia $^{-1}$ porém ultrapassam 5,0 $\mathrm{MJ} \mathrm{m}^{-2} \mathrm{dia}^{-1}$.

Em relação às medidas de 2004, assim como obtido para um cafezal adulto (Angelocci et al., 2008), o saldo de radiação do renque de cafeeiros apresentou boa correlação com a radiação solar global $(\mathrm{Qg})$ e o saldo de radiação de gramado (Rn) (Figura 3), com bons ajustes tanto na forma linear quanto quadrática e com maiores valores de $\mathrm{R}^{2}$ nessa segunda forma.

Contudo, observa-se nitidamente uma dispersão dos pontos em duas porçóes do campo de variação (histerese) para as medidas feitas com AF de 3,64 $\mathrm{m}^{2} \mathrm{pl}^{-1}$, uma de relação praticamente linear na parte inferior de distribuição dos dados e que representa medidas obtidas no período da manhã, e outra de relação hiperbólica na parte superior, representando, em sua grande maioria, dados obtidos no período da tarde (Figuras 3a,b).

Explica-se essa histerese pela modificação do padrão de interceptação de radiação solar, principalmente da sua componente radiação direta, pela folhagem do renque ao longo do dia. Tomando-se um dia de céu com baixa nebulosidade e na condiçáo de área foliar observada no período, em que a folhagem concentrava-se essencialmente na extremidade dos ramos devido à carga de frutos nos ramos superiores, observa-se na figura 4 que, com a crescente elevação solar até o meio do dia, o Rnc apresentou correlação praticamente linear com Qg. Entretanto, no período entre 12 h e 13 h30 verifica-se, devido à orientação dos renques, que a radiação solar direta era interceptada basicamente pela face superior dos renques, reduzindo-se assim a área total de interceptação e, consequentemente, os valores de Rnc durante o período citado (Figura 4). A partir das 13h30, a face lateral do renque voltada aproximadamente para oeste participava bastante, juntamente com a face superior, da interceptação da radiação solar, aumentando novamente a magnitude de Rnc por um certo período mas, com o avanço do período da tarde, ela posteriormente decrescia, devido à reduçáo do Qg. Riou et al. (1989) apresentam

Tabela 1. Fenologia, área foliar por planta $(\mathrm{AF})$, área foliar por metro linear de renque $\left(\mathrm{AF}_{\mathrm{h}}\right)$ e número de dias de medições (N.M.)

\begin{tabular}{|c|c|c|c|c|}
\hline Meses/ano & Fenologia cafezal & AF $\left(\mathrm{m}^{2} \mathrm{pl}^{-1}\right)$ & $\operatorname{AF}_{h}\left(m^{2} m^{-1}\right)$ & N.M. \\
\hline Ago/2004 & * & 3,64 & 4,04 & 6 \\
\hline Set/2004 & * & 1,42 & 1,57 & 7 \\
\hline Fev-mar/2005 & $* *$ & 11,36 & 12,62 & 27 \\
\hline Mar-abr/2005 & ** & 9,58 & 10,64 & 13 \\
\hline Abr/2005 & ** & 7,77 & 8,64 & 10 \\
\hline Abr/2005 & $* *$ & 5,97 & 6,64 & 5 \\
\hline Abr-maio/2005 & $* *$ & 4,21 & 4,68 & 6 \\
\hline
\end{tabular}

*Final do repouso, com presença de frutos - início vegetação e formaçấo das gemas foliares; ** Vegetação e formação das gemas foliares - indução e maturação das gemas florais. Fonte das descriçóes fenológicas *,**: Camargo e Camargo (2001).

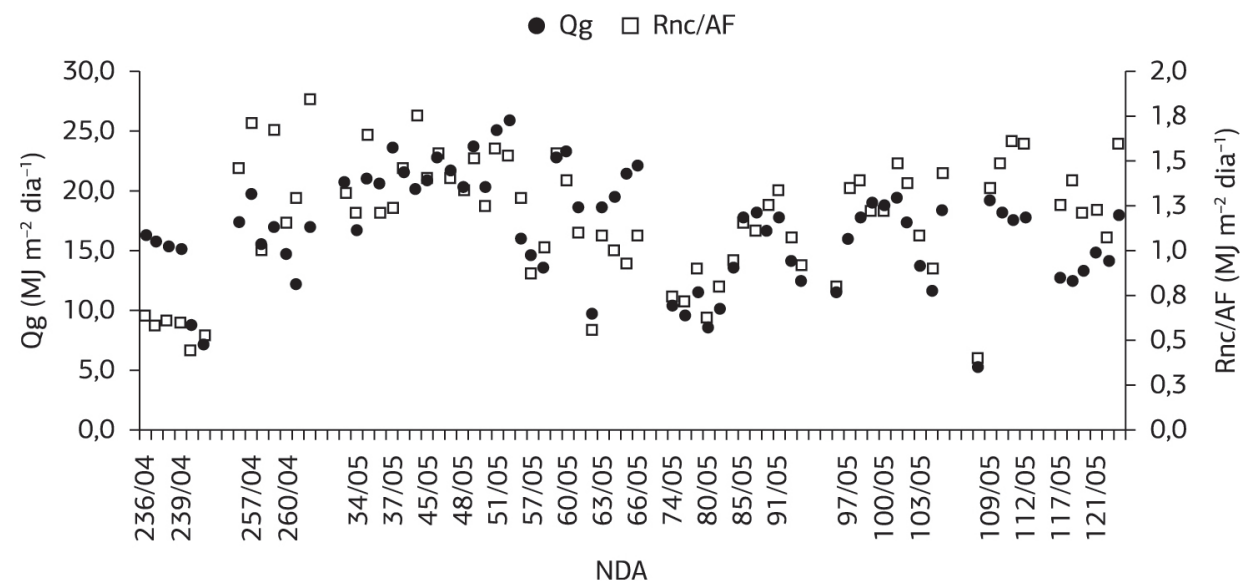

Figura 2. Variação diária da radiaçáo solar global $(\mathrm{Qg})$ e do saldo de radiação por unidade de área foliar dos cafeeiros (Rnc/AF). NDA: número sequencial do dia no ano. 

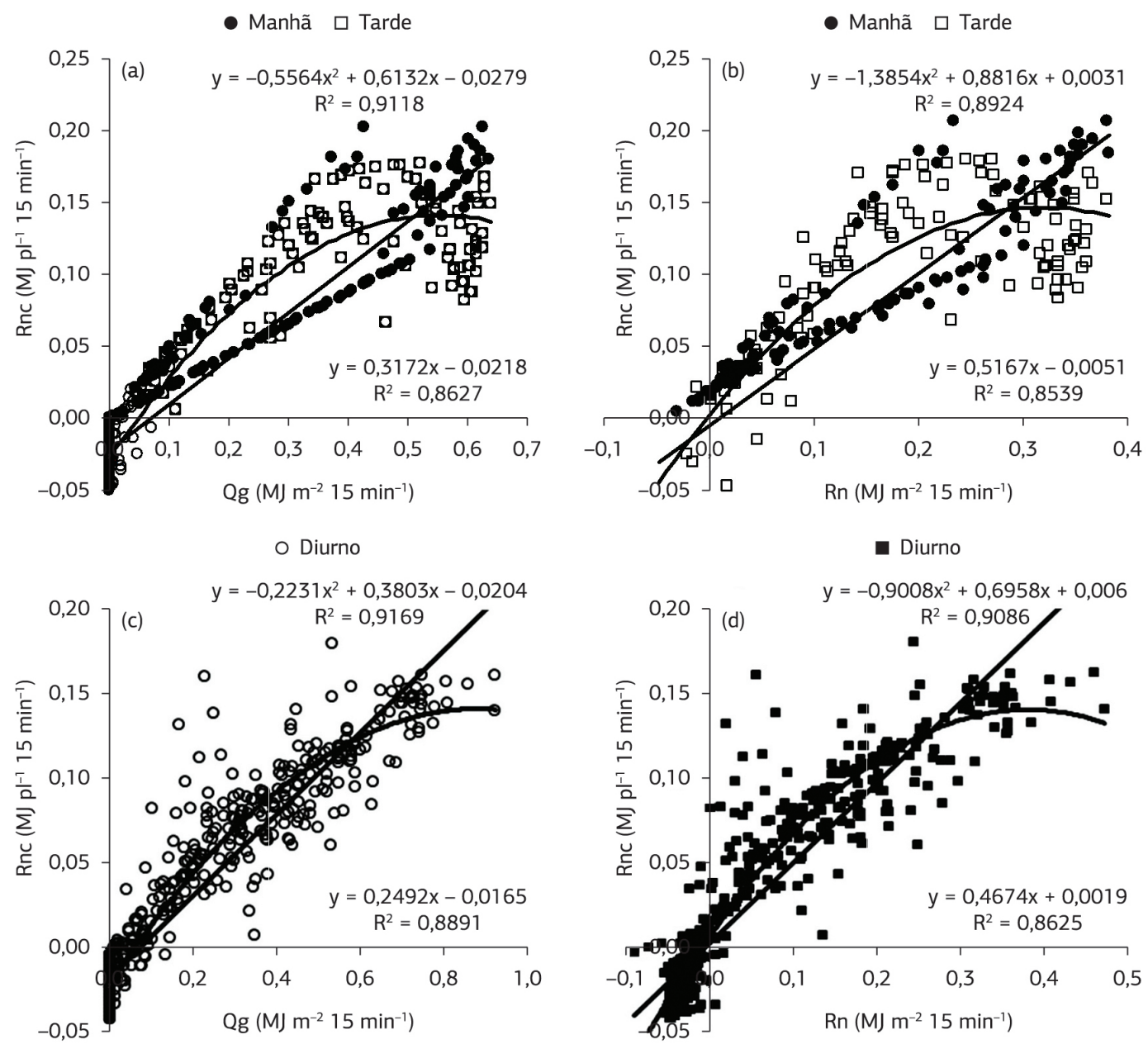

Figura 3. Correlação do saldo de radiação por cafeeiro (Rnc) com a radiação solar global $(\mathrm{Qg})(\mathbf{a}, \mathbf{c})$ e saldo de radiação de gramado (Rn) (b, d) na escala de 15 minutos; áreas foliares de $3,64 \mathrm{~m}^{2} \mathrm{pl}^{-1}(\mathbf{a}, \mathbf{b})$ e $1,42 \mathrm{~m}^{2} \mathrm{pl}^{-1}(\mathbf{c}, \mathbf{d})$.

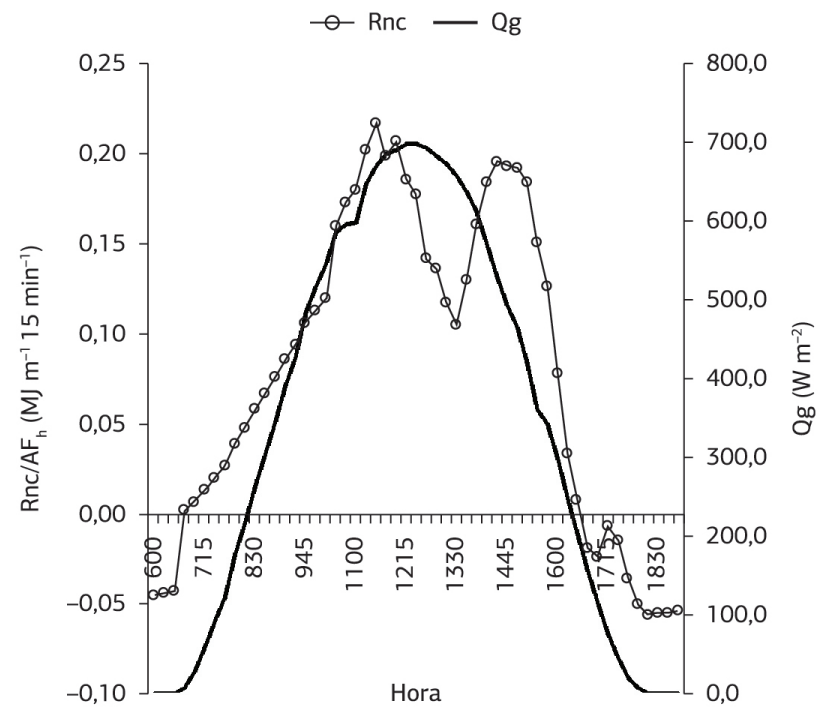

Figura 4. Variação temporal da radiação solar global $(\mathrm{Qg})$ e do saldo de radiaçáo normalizado por unidade de área foliar $\left(\mathrm{Rnc}_{\mathrm{AF}}\right)$, na condição de $\mathrm{AF}_{\mathrm{h}}$ igual a $4,04 \mathrm{~m}^{2} \mathrm{~m}^{-1}$, para um dia de céu claro (dia do ano: 23/7/2004). padrão similar para as curvas de radiação solar interceptada por renques de vinhas orientados no sentido norte-sul, na França.

Ao mesmo tempo, o tamanho das plantas em relação ao espaçamento entre renques $(3,5 \mathrm{~m})$ expunha praticamente toda a área de entrelinhas (solo e plantas eventuais) à radiação solar global, causando o aquecimento desses corpos adjacentes ao renque de cafeeiros. A consequência dessa condição acaba sendo um aumento da emissão de ondas longas por tais corpos em todas as direçóes, incluindo-se em direção aos cafeeiros, tornando o saldo de radiação do período da tarde igual ou superior ao da manhã (Figuras 3a,b). Esse padrão se opõe às observaçóes realizadas em dosséis que recobrem completamente o solo, nos quais valores menores de saldo de radiação normalmente são observados no período da tarde devido ao aumento da temperatura da folhagem causar uma maior emissão de radiação de onda longa pela vegetação, superior à contrarradiação emitida pela atmosfera (Souza Filho et al., 2006). 
Nas mediçóes de Rnc para o mesmo trecho de renque quando a AF média era de apenas $1,42 \mathrm{~m}^{2} \mathrm{pl}^{-1}$, a histerese entre as curvas da correlação de Rnc e Qg não é observada (Figura 3c). O saldo de radiação dos cafeeiros equivaleu a $46,42 \%$ do saldo de radiação de um metro de superfície gramada (Figura 3d). Pelo fato de não ter sido observada a histerese nessa condição de área foliar, nessas duas figuras os dados náo foram representados separadamente para os períodos da manhã e da tarde. A partir dos valores de índice de área foliar (IAF) dos cafeeiros, por área de projeção da copa $\left(0,9 \mathrm{~m}^{2}\right)$ ter-se-iam plantas com IAF de 4,04 $\left(3,64 \mathrm{~m}^{2} \mathrm{pl}^{-1}\right) \mathrm{e}$ IAF de $1,57\left(1,42 \mathrm{~m}^{2} \mathrm{pl}^{-1}\right)$, que expunham, respectivamente,
Rnc equivalentes a 50,28\% e 46,42\% do saldo de radiação de um metro quadrado de gramado (Figuras 3b,d). A partir da conceituação de que um gramado padrão possui $\mathrm{IAF} \cong 3$, observa-se que a geometria paralelepipedal da copa de cafeeiros expõe diferentemente a folhagem à radiação solar global em comparação à superfície plana gramada e, a partir da redução da folhagem, percebe-se uma relação não linear entre a absorbância de energia e a AF.

Em 2005, as desfolhas manuais no trecho de renque conduziram a cinco novos valores distintos de AF (Tabela 1), permitindo uma ampliação da análise do efeito da folhagem no estabelecimento do balanço de radiação. As sucessivas
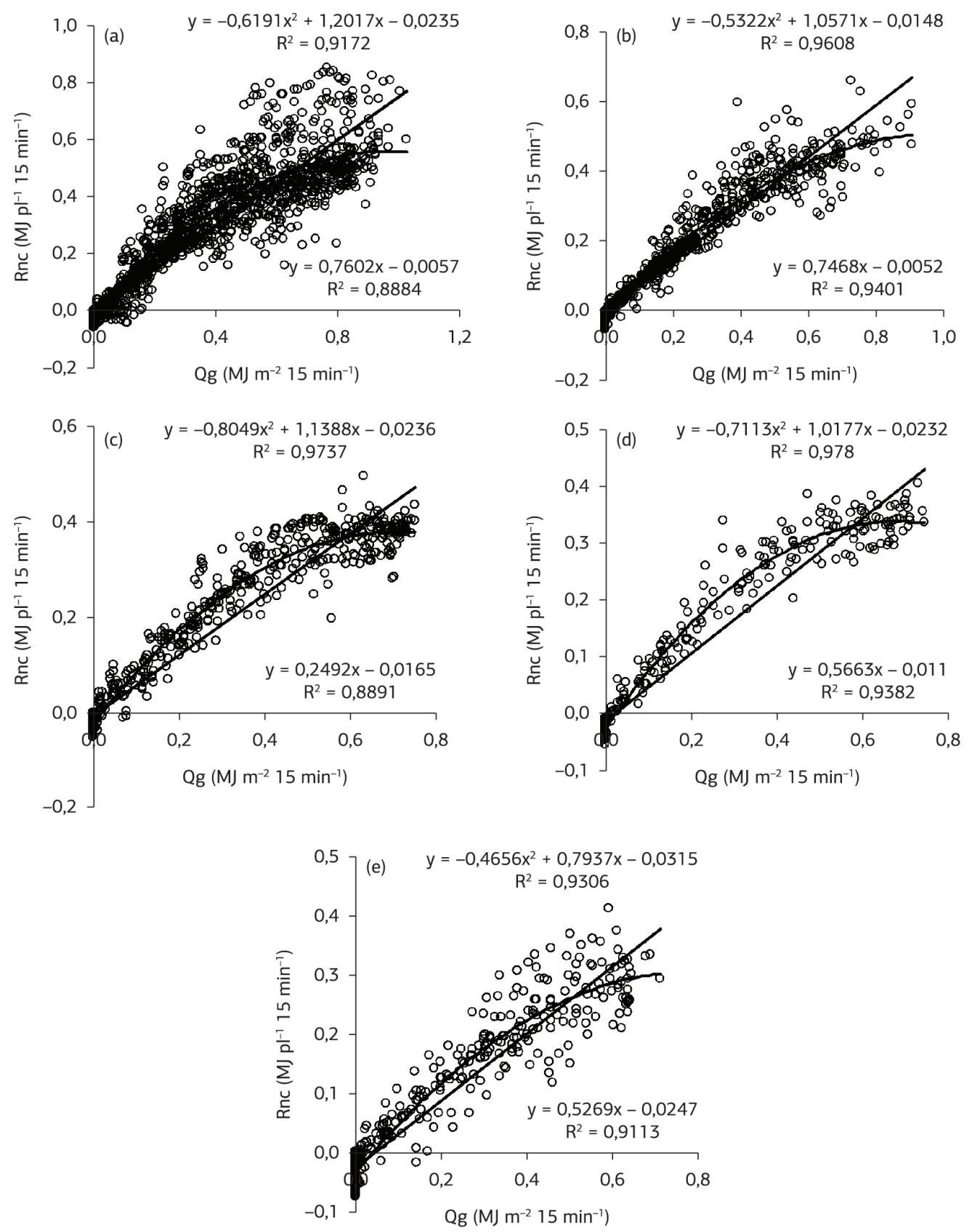

Figura 5. Relação do saldo de radiação por cafeeiro (Rnc) com a radiação solar global (Qg) na escala de 15 minutos; áreas foliares de $11,36 \mathrm{~m}^{2} \mathrm{pl}^{1}$ (a), 9,58 $\mathrm{m}^{2} \mathrm{pl}^{1}$ (b), 7,77 $\mathrm{m}^{2} \mathrm{pl}^{1}$ (c), 5,97 $\mathrm{m}^{2} \mathrm{pl}^{1}$ (d) e 4,21 $\mathrm{m}^{2} \mathrm{pl}^{1}$ (e). 
reduçóes de AF afetaram diretamente a absorção de energia radiante, mas sempre mantendo um bom ajuste (Figura 5). Além da influência da $\mathrm{AF}$, a redução progressiva da $\mathrm{Qg}$ ao longo das mediçóes em 2005 (Figura 2) influenciou diretamente na formação do saldo de radiação (Figura 5).

Igualmente ao observado para trecho de renque em 2004 (Figura 3), há uma relação direta, porém não proporcional, entre Rnc e área foliar das plantas. $\mathrm{O}$ aumento da AF em um volume pequeno como o da copa dos cafeeiros em formação acentuou o autossombreamento das folhas. Desse modo, a radiação solar acaba extinta nas porçôes superior e externa do dossel, como observado por Marin et al. (2003), não incidindo em grande profundidade na folhagem e gerando relaçóes específicas de Rnc com Qg para cada área foliar (Figura 5). Observaram-se, de novo, bons ajustes lineares e quadráticos, melhores nesses últimos entre Rnc e Qg na escala de 15 minutos e, também, o efeito da diminuição da área foliar, pela redução dos coeficientes $a$ e $b$ das equaçôes, sendo que para as maiores áreas foliares $\left(11,36\right.$ e 9,58 $\left.\mathrm{m}^{2} \mathrm{pl}^{-1}\right)$ os valores desses coeficientes são muito próximos.

Do mesmo modo, bons ajustes lineares e quadráticos foram obtidos entre Rnc e Rn em relação às avaliações de 2005 (Figura 6), novamente específicos para cada um dos valores de AF.
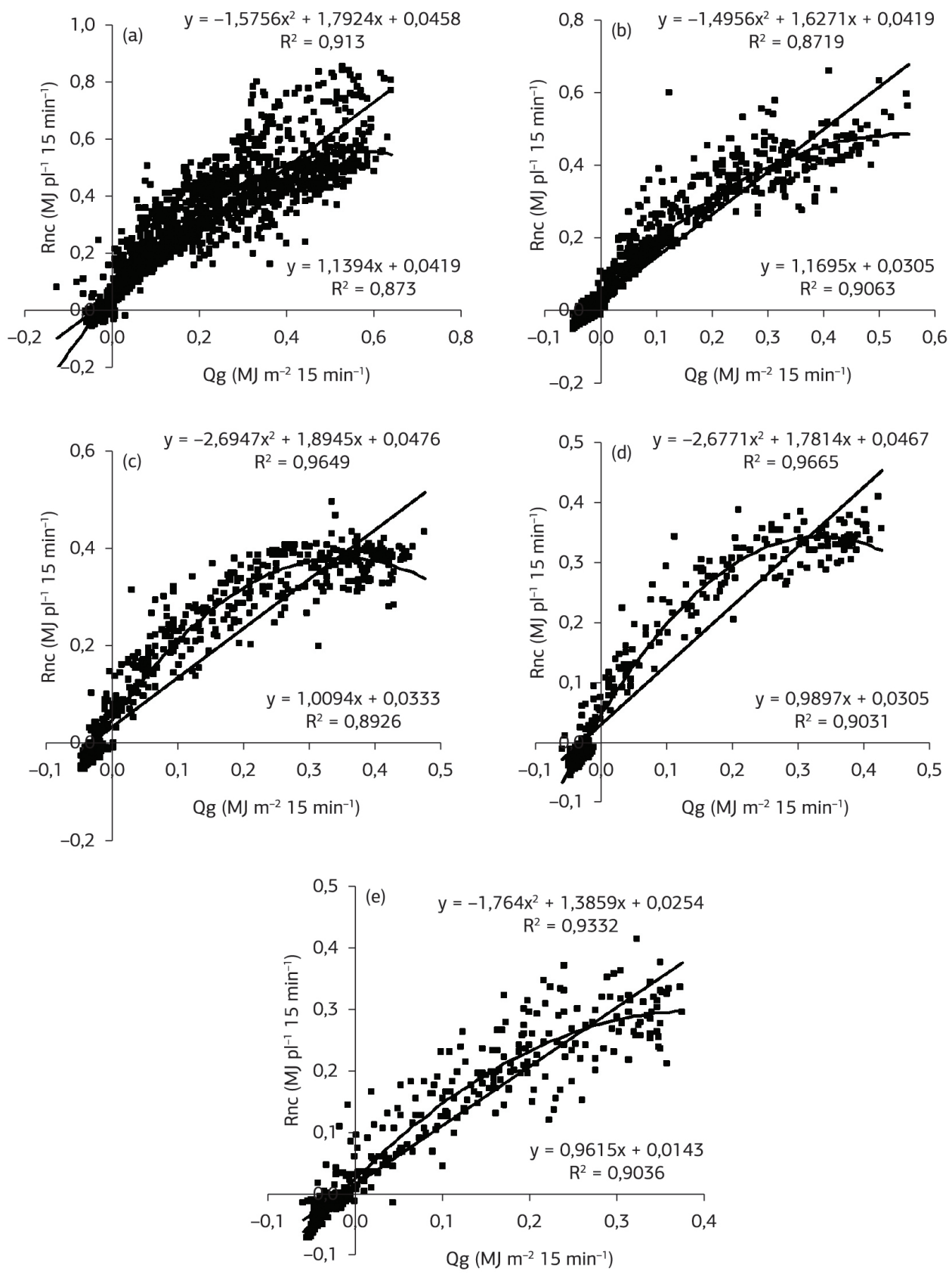

Figura 6. Relação do saldo de radiação por cafeeiro (Rnc) com o saldo de radiação de gramado (Rn) na escala de 15 minutos; áreas foliares de $11,36 \mathrm{~m}^{2} \mathrm{pl}^{1}$ (a), 9,58 $\mathrm{m}^{2} \mathrm{pl}^{1}$ (b), 7,77 $\mathrm{m}^{2} \mathrm{pl}^{1}$ (c), 5,97 $\mathrm{m}^{2} \mathrm{pl}^{1}$ (d) e 4,21 $\mathrm{m}^{2} \mathrm{pl}^{1}$ (e). 
Normalizando-se o saldo de radiaçáo da copa por unidade de área foliar (Rnc/AF) e correlacionando-se os resultados às variáveis $\mathrm{Qg}$ e $\mathrm{Rn}$, nas escalas temporais de 15 minutos e horária, mantêm-se ajustes lineares específicos - para verificar mais facilmente o efeito da área foliar, trabalhou-se com os coeficientes das regressóes lineares na escala de 15 minutos e horária. Com a redução da área foliar e, concomitantemente, do autossombreamento das folhas, tem-se acréscimos nos valores do coeficiente angular "a", com bons ajustes para todas as condiçôes de $\mathrm{AF}$, de acordo com valores de $\mathrm{R}^{2}$ (Tabela 2). $\mathrm{Na}$ figura 7 são observados bons ajustes exponenciais negativos desses coeficientes angulares com a variaçáo da área foliar média por planta, o que pode explicar o bom desempenho de modelos matemáticos embasados na Lei de Beer, empregados tanto na estimativa da interceptação de energia radiante por copa de arbóreas (Angelocci et al., 2008; Oyarzún et al., 2011) quanto de forma inversa, na estimativa da densidade de folhagem das copas (Antunes Junior et al., 2009).

Coeficientes angulares ajustados nas relaçóes de Rnc/AF com Qg ou Rn, em ambas escalas temporais, referentes a AF de $3,64 \mathrm{~m}^{2} \mathrm{pl}^{-1}$ (pontos circundados, Figura 7) aumentaram a dispersão dos pontos em torno das linhas das regressóes. Nesse momento do ano de 2004, os cafeeiros estavam carregados de frutos, sendo muito provável que o avanço da maturação dos frutos, com alteraçáo da cor de verde para o vermelho, tenha interferido com a energia radiante, reduzindo a absorbância global das plantas (Silva et al., 2008).

Assim como observado por Smith et al. (1997), ajustes específicos para cada AF média foram gerados para a correlação Rnc/AF e Qg ou Rn para os valores integrados na escala diurna (Tabela 3). Nesse caso, os resultados não sustentam a hipótese de que o saldo de radiaçáo normalizado por unidade de área foliar guarda sempre uma função linear com o saldo de radiação de gramado, proposta por Pereira et al. (2001; 2007), que observaram ajustes lineares $(y=a . x)$, com altos coeficientes de determinação das regressóes entre o saldo de radiação de espécies arbóreas e o saldo de radiação de superfície gramada, e valores de "a" entre 0,262 (macieira) e 0,318 (oliveira e nogueira), acima dos valores de "a" obtidos para a correlação Rnc/AF e Rn (Tabela 3). Por outro lado, sáo observadas na tabela 3 acentuadas diferenças de valores de $\mathrm{R}^{2}$ para correlaçóes diurnas, com valores em alguns casos muito baixos e certamente náo significativos, decorrentes do reduzido número de dias de amostragem para algumas $\mathrm{AF}$ (Tabela 1) e também de valores de Rnc/AF muito similares, devido à pequena amplitude de variação dos valores de $\mathrm{Qg}$ e Rnc integrados no período diurno. Essa última condição

Tabela 2. Coeficientes de regressốes entre o saldo de radiação por unidade de área foliar dos cafeeiros (y, $\mathrm{MJ} \mathrm{m}^{-2} \mathrm{t}^{-1}$ ) e a radiação solar global $\left(\mathrm{x}_{1}, \mathrm{MJ} \mathrm{m}^{-2} \mathrm{t}^{-1}\right)$ e o saldo de radiação de gramado $\left(\mathrm{x}_{2}, \mathrm{MJ} \mathrm{m}^{-2} \mathrm{t}^{-1}\right)$ nas escalas de 15 minutos e horária

\begin{tabular}{|c|c|c|c|c|c|c|c|c|c|c|c|c|}
\hline \multirow{3}{*}{ AF } & \multicolumn{6}{|c|}{$15 \min (t)$} & \multicolumn{6}{|c|}{ Horária (t) } \\
\hline & \multicolumn{3}{|c|}{ Rnc/AF x Qg } & \multicolumn{3}{|c|}{ Rnc/AF x Rn } & \multicolumn{3}{|c|}{ Rnc/AF x Qg } & \multicolumn{3}{|c|}{ Rnc/AF x Rn } \\
\hline & $\mathbf{a}$ & b & $\mathbf{R}^{2}$ & a & b & $\mathbf{R}^{2}$ & $\mathbf{a}$ & b & $\mathbf{R}^{2}$ & a & b & $\mathbf{R}^{2}$ \\
\hline $3,64^{(2004)}$ & 0,087 & $-0,006$ & 0,863 & 0,142 & $-0,001$ & 0,854 & 0,087 & $-0,024$ & 0,880 & 0,142 & $-0,005$ & 0,864 \\
\hline $1,42^{(2004)}$ & 0,172 & $-0,011$ & 0,853 & 0,323 & 0,001 & 0,827 & 0,174 & $-0,048$ & 0,907 & 0,327 & 0,004 & 0,878 \\
\hline $11,36^{(2005)}$ & 0,067 & $-0,001$ & 0,940 & 0,100 & 0,004 & 0,873 & 0,068 & $-0,003$ & 0,910 & 0,102 & 0,014 & 0,893 \\
\hline $9,58^{(2005)}$ & 0,078 & $-0,001$ & 0,940 & 0,122 & 0,003 & 0,906 & 0,078 & $-0,003$ & 0,955 & 0,124 & 0,012 & 0,925 \\
\hline $7,77^{(2005)}$ & 0,083 & $-0,001$ & 0,934 & 0,123 & 0,004 & 0,893 & 0,083 & $-0,006$ & 0,946 & 0,130 & 0,016 & 0,906 \\
\hline $5,97^{(2005)}$ & 0,095 & $-0,002$ & 0,938 & 0,166 & 0,005 & 0,903 & 0,095 & $-0,008$ & 0,940 & 0,166 & 0,020 & 0,903 \\
\hline $4,21^{(2005)}$ & 0,114 & $-0,005$ & 0,910 & 0,208 & 0,003 & 0,904 & 0,114 & $-0,021$ & 0,925 & 0,210 & 0,012 & 0,932 \\
\hline
\end{tabular}
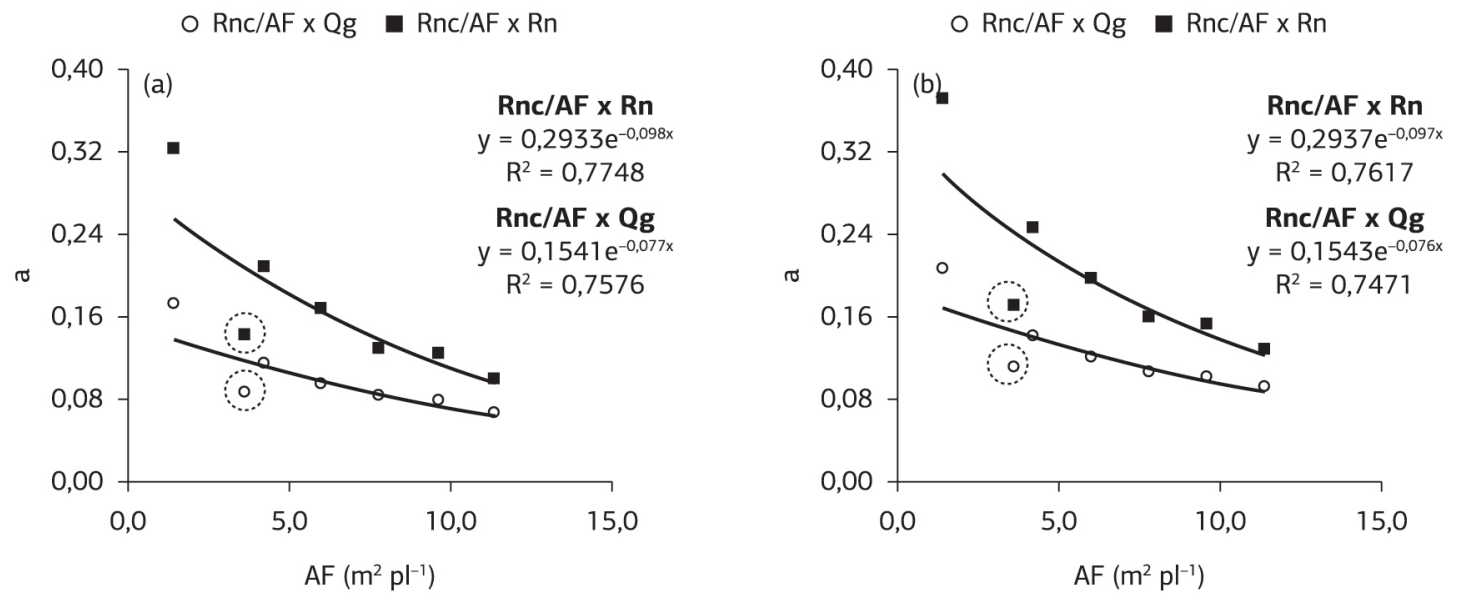

Figura 7. Relaçóes da área foliar (AF) dos cafeeiros com o coeficiente angular (a) das equaçóes de regressão entre o saldo de radiação por unidade de área foliar e a radiação solar global ou o saldo de radiação do gramado (Tabela 2), para as escalas de 15 minutos (a) e horária (b). 
Tabela 3. Valores dos coeficientes das equações lineares de regressão $(R n c / A F=a \cdot Q g+b ; R n c / A F=a \cdot R n+b)$ entre o saldo de radiação dos cafeeiros por unidade de área foliar (Rnc/AF; $\left.\mathrm{MJ} \mathrm{m}^{-2} \mathrm{dia}^{-1}\right) \mathrm{com}$ a radiação solar global $\left(\mathrm{Qg} ; \mathrm{MJ} \mathrm{m}^{-2}\right.$ dia $^{-1}$ ) e o saldo de radiação de gramado $\left(\mathrm{Rn}, \mathrm{MJ} \mathrm{m}{ }^{-2} \mathrm{dia}^{-1}\right)$

\begin{tabular}{|c|c|c|c|c|c|c|}
\hline \multirow{2}{*}{$A F\left(m^{2} \mathrm{pl}^{-1}\right)$} & \multicolumn{3}{|c|}{ Rnc/AF x Qg } & \multicolumn{3}{|c|}{ Rnc/AF x Rn } \\
\hline & a & b & $\mathbf{R}^{2}$ & a & b & $\mathbf{R}^{2}$ \\
\hline 3,64 & 0,0150 & 0,3670 & 0,7697 & 0,0283 & 0,4263 & 0,7180 \\
\hline 1,42 & 0,0750 & 0,2200 & 0,3395 & 0,1237 & 0,8324 & 0,3719 \\
\hline 11,36 & 0,0607 & 0,0730 & 0,5091 & 0,1185 & 0,1740 & 0,7056 \\
\hline 9,58 & 0,0600 & 0,1743 & 0,8370 & 0,1045 & 0,4133 & 0,9673 \\
\hline 7,77 & 0,0670 & 0,1309 & 0,7642 & 0,1057 & 0,5233 & 0,5129 \\
\hline 5,97 & 0,0822 & 0,0096 & 0,9075 & 0,1952 & 0,2468 & 0,9634 \\
\hline 4,21 & 0,0408 & 0,5639 & 0,1548 & 0,1467 & 0,5327 & 0,6744 \\
\hline
\end{tabular}

AF é a área foliar média por cafeeiro e $\mathrm{R}^{2}$ é o coeficiente de determinação.

promove concentração dos pontos de correlação $\mathrm{Rnc} \times \mathrm{Qg}$ ou Rnc $\times$ Rn.

A partir das equaçóes das análises de regressão entre Rnc/AF e Qg ou Rn (Tabela 3) observam-se coeficientes lineares (b) positivos para a ocorrência tanto de Qg como de Rn igual a zero. A geometria adotada para a medida do saldo de radiação, que de fato contempla a geometria do cultivo, possibilitou a mensuração da radiação de onda longa emitida para a atmosfera, contrabalanceada por energia de onda longa emitida tanto pela atmosfera quanto da superfície e vegetação circundante em direção ao renque, que nesse caso sustentam a ocorrência de saldo de radiação (Rnc/AF) positivo nos períodos de medida em que Qg ou Rn estão próximos de zero, no início ou no final do período diurno.

\section{CONCLUSÃO}

A arquitetura e área foliar das plantas bem como a geometria de plantio interferem diretamente na formação do saldo de radiação das copas dos cafeeiros, evidenciando o autossombreamento da folhagem e assim determinando correlaçôes específicas do balanço de energia da folhagem com a radiaçáo solar global e o saldo de radiação de gramado para cada área foliar em todas as escalas temporais avaliadas.

\section{REFERÊNCIAS}

ANDRÉ, R.G.B.; MENDONÇA, J.C.; MARQUES, V.S.; PINHEIRO, F.M.A.; MARQUES, J. Aspectos energéticos do desenvolvimento da cana-de-açúcar. Parte 1: balanço de radiação e parâmetros derivados. Revista Brasileira de Meteorologia, v.25, p.375-382, 2010. http:// dx.doi.org/10.1590/S0102-77862010000400012

ANGELOCCI, L.R.; MARIN, F.R.; PILAU, F.G.; RIGHI, E.Z.; FAVARIN, J.L. Radiation balance of coffee hedgerows. Revista Brasileira de Engenharia Agrícola e Ambiental, v.12, p.274-281, 2008. http:// dx.doi.org/10.1590/S1415-43662008000300008

ANGELOCCI, L.R.; VILLA NOVA, N.A.; COELHO FILHO, M.A.; MARIN, F.R. Measurements of net radiation absorbed by isolated acid lime trees (Citrus latifolia Tanaka). Journal of Horticultural Science \& Biotechnology, v.79, p.699-703, 2004.

ANTUNES JUNIOR, M.Z.; FERRONATO, A.; FERRONATO, S.D.; RODRIGUES, K.; GALLON, M.M.P.; GOMES, N.M.G.; STIEVEN, A.C.; JÚNIOR, J.H.C. Métodos não destrutivos para estimativa de densidade de área foliar em mangueira. Pesquisa Agropecuária Brasileira, v.44, p.1624-1630, 2009. http://dx.doi. org/10.1590/S0100-204X2009001200009

BENINCASA, M.M.P. Análise de crescimento de plantas (noçóes básicas). Jaboticabal: FUNEP, 2003. 41p.

CAMARGO, Â.P.; CAMARGO, M.B.P. Definição e esquematização das fases fenológicas do cafeeiro arábica nas condiçôes tropicais do Brasil. Bragantia, v.60, p.65-68, 2001.

CARRASCO, M.; ORTEGA-FARÍAS, S. Evaluation of a model to simulate net radiation over a vineyard cv. Cabernet Sauvignon. Chilean Journal of Agricultural Research, v.68, p.156-165, 2008. http://dx.doi.org/10.4067/S0718-58392008000200005

FLUMIGNAN, D.L.; FARIA, R.T. Evapotranspiração e coeficientes de cultivo de cafeeiros em fase de formação. Bragantia, v.68, p.269278, 2009. http://dx.doi.org/10.1590/S0006-87052009000100029

GOMIDE, M.B; LEMOS, O.V.; TOURINO, D.; CARVALHO, M.M.; CARVALHO, J.G.; DUARTE, G.S. Comparaçấo entre métodos de determinação da área foliar em cafeeiros Mundo Novo e Catuí. Ciência e Prática, v.1, p.118-123, 1977.

GREEN, S.; McNAUGHTON, K.; WÜNSCHE; J.N.; CLOTHIER, B. Modeling light interception and transpiration of apple tree canopies. Agronomy Journal, v.95, p.1380-1387, 2003. doi:10.2134/ agronj2003.1380

GREEN, S.R.; GREER, D.H.; WÜNSCHE, J.N.; CASPARI, H. Measurement of light interception and utilization in an apple orchard. Acta Horticulturae, v.557, p.369-376, 2001.

JACKSON, J.E.; PALMER, J.W. A simple model of light transmission and interception by discontinuous canopies. Annals of Botany, v.44, p.381-383, 1979 .

JARAMILLO-BOTERO, C.; SANTOS, R.H.S.; MARTINEZ, H.E.P.; CECON, P.R.; FARDIN, M.P. Production and vegetative growth of coffee trees under fertilization and shade levels. Scientia Agricola, v.67, p.639-645, 2010. http://dx.doi.org/10.1590/S010390162010000600004 
KARASAWA, S.; ANGELOCCI, L.R.; FAVARIN, J.L. Evapotranspiração de cafezal irrigado por gotejamento e sua relação com a evapotranspiração de referência. Revista Brasileira de Agrometeorologia, v.15, p.01-13, 2007.

LANDSBERG, J.J.; BEADLE, C.C.; BISCOL, P.V.; BUTLER, D.R.; DAVIDSON, B.; INCOLL, L.D.; JAMES, G.B.; JARVIS, P.G.; MARTIN, P.J.; NEILSON, R.E.; POWELL, D.B.B.; SLACK, E.M.; THORPE, M.R.; TURNER, N.C.WARRIT, B.; WATTS, W.R. Diurnal energy, water and $\mathrm{CO}_{2}$ exchanges in an apple (Malus pumila) orchard. Journal of Applied Ecology, v.12, p.645-683, 1975.

MARIN, F.R.; ANGELOCCI, L.R.; RIGHI, E.Z.; SENTELHAS, P.C. Evapotranspiration and irrigation requirements of a coffee plantation in Southern Brazil. Experimental Agriculture, v.41, p.187-197, 2005.

MARIN, F.R.; SANTIAGO, A.V.; RIGHI, E.Z.; SENTELHAS, P.C.; ANGELOCCI, L.R.; MAGGIOTTO, S.R.; PEZZOPANE, J.R.M. Solar radiation interception and its relation with transpiration in different coffee canopy layers. Revista Brasileira de Agrometeorologia, v.11, p.1-6, 2003.

McNAUGHTON, K.G.; GREEN, S.R.; BLACK, T.A.; TYNAN, B.R.; EDWARDS, W.R.N. Direct measurement of net radiation and photosynthetically active radiation absorbed by a single plant. Agricultural and Forest Meteorology, v.62, p.87-107, 1992. DOI:10.1016/0168-1923(92)90007-Q

OYARZÚN, R.; STÖCKLE, C.; WU, J.; WHITING, M. In field assessment on the relationship between photosynthetic active radiation (PAR) and global solar radiation transmittance through discontinuous canopies. Chilean Journal of Agricultural Research, v.71, p.122-131, 2011. http://dx.doi.org/10.4067/S0718-58392011000100015

OYARZÚN, R.A.; STOCKLE, C.O.; WHITING, M.D. A simple approach to modeling radiation interception by fruit tree orchards. Agricultural and Forest Meteorology, v.142, p.12-24, 2007. http:// dx.doi.org/10.1016/j.agrformet.2006.10.004

PEREIRA, A.R.; ANGELOCCI, L.R.; VILLA NOVA, N.A.; SENTELHAS, P.C. Estimating single tree net radiation using grass net radiation and tree leaf area. Revista Brasileira de Agrometeorologia, v.9, p.187-192, 2001.

PEREIRA, A.R.; GREEN, S.; VILLA NOVA, N.A. Relationships between single tree canopy and grass net radiations. Agricultural and
Forest Meteorology, v.142, p.45-49, 2007. http://dx.doi.org/10.1016/j. agrformet.2006.11.003

RIGHI, E.Z.; ROBERTO, L.; MARIN, F.R. Energy balance of a young drip-irrigated coffee crop in southeast Brazil: an analysis of errors and reliability of measurements by the Bowen ratio method. Revista Brasileira de Agrometeorologia, v.15, p.267-279, 2007.

RIOU, C.; VALANCOGNE, C.; PIERI, P. Um modèle simple d'interception du rayonnement solaire par la vigne - vérication expérimentale. Agronomie, v.9, p.441-450, 1989.

RITCHIE, J.E. Model for predicting evaporation from a row crop with incomplete cover. Water Resources Research, v.8, p.1204-1213, 1972.

SAUER, T.J.; SINGER, J.W.; PRUEGER, J.H.; DESUTTER, T.M.; HATFIELD, J.L. Radiation balance and evaporation partitioning in a narrow-row soybean canopy. Agricultural and Forest Meteorology, v.145, p.206-214, 2007. http://dx.doi.org/10.1016/j.agrformet.2007.04.015

SENTELHAS, P.C.; NASCIMENTO, A.L.C. Variação sazonal da relaçáo entre o saldo de radiaçáo e a radiaçáo solar global. Revista Brasileira de Agrometeorologia, v.18, p.71-77, 2003.

SILVA, T.V.; RESENDE, E.D.; VIANA, A.P.; PEREIRA, S.E.M.F.; CARLOS, L.A.; VITORAZI, L. Determinação da escala de coloração da casca e do rendimento em suco do maracujá-amarelo em diferentes épocas de colheita. Revista Brasileira de Fruticultura, v.30, p.880884, 2008. http://dx.doi.org/10.1590/S0100-29452008000400007

SMITH, D.M.; JARVIS, P.G.; ODONGO, J.C.W. Energy budgets of windbreak canopies in the Sahel. Agricultural and Forest Meteorology, v.86, p.33-49, 1997. http://dx.doi.org/10.1016/S0168-1923(96)02416-1

SOUZA FILHO, J.D.C.; RIBEIRO, A.; COSTA, M.H.; COHEN, J.C.P.; ROCHA, E.J.P. Variação sazonal do balanço de radiação em uma floresta tropical no nordeste da Amazônia. Revista Brasileira de Meteorologia, v.21, p.318-330, 2006.

SOUZA, P.J.O.P.; ROCHA, E.J.P.; RIBEIRO, A.; SOUZA, E.B. Radiation balance in a soybean ecosystem in the Amazonia. Revista Ciência Agronômica, v.41, p.582-592, 2010. http://dx.doi.org/10.1590/ S1806-66902010000400010

THORPE, M.R. Net radiation and transpiration of apple trees in rows. Agricultural and Forest Meteorology, v.19, p.41-57, 1978. http://dx.doi.org/10.1016/0002-1571(78)90037-7 